\title{
In Situ Fabrication and Reactivation of Highly Selective and Stable Ag Catalysts for Electrochemical $\mathrm{CO}_{2}$ Conversion
}

\author{
Ming Ma, ${ }^{* \dagger \odot}$ Kai Liu, ${ }^{\dagger}$ Jie Shen, ${ }^{\ddagger}$ Recep Kas, ${ }^{\dagger}$ and Wilson A. Smith*, ${ }^{\dagger}$ \\ ${ }^{\dagger}$ Materials for Energy Conversion and Storage (MECS), Department of Chemical Engineering, Delft University of Technology, Van \\ der Maasweg 9, 2629 HZ Delft, The Netherlands \\ ${ }^{\ddagger}$ QuTech and Kavli Institute of Nanoscience, Delft University of Technology, Delft 2600 GA, The Netherlands

\section{Supporting Information}

ABSTRACT: In this work, the highly selective and stable electrocatalytic reduction of $\mathrm{CO}_{2}$ to $\mathrm{CO}$ on nanostructured $\mathrm{Ag}$ electrocatalysts is presented. The $\mathrm{Ag}$ electrocatalysts are synthesized by the electroreduction of $\mathrm{Ag}_{2} \mathrm{CO}_{3}$ formed by in situ anodic-etching of $\mathrm{Ag}$ foil in a $\mathrm{KHCO}_{3}$ electrolyte. After 3 min of this etching treatment, the $\mathrm{Ag}_{2} \mathrm{CO}_{3}$ derived nanostructured $\mathrm{Ag}$ electrocatalysts are capable of producing $\mathrm{CO}$ with up to $92 \%$ Faradaic efficiency at an overpotential as low as $290 \mathrm{mV}$, which surpasses all of the reported Ag catalysts at identical conditions to date. In addition, the anodic-etched $\mathrm{Ag}$ retained $\sim 90 \%$ catalytic selectivity in the electroreduction of $\mathrm{CO}_{2}$ to $\mathrm{CO}$ for more than $100 \mathrm{~h}$. The $\mathrm{Ag}_{2} \mathrm{CO}_{3}$-derived $\mathrm{Ag}$ is able to facilitate the activation of $\mathrm{CO}_{2}$ via reduction of the activation energy barrier of the initial electron transfer and provide an increased number of active sites, resulting in the dramatically improved catalytic activity for the reduction of $\mathrm{CO}_{2}$ to $\mathrm{CO}$.

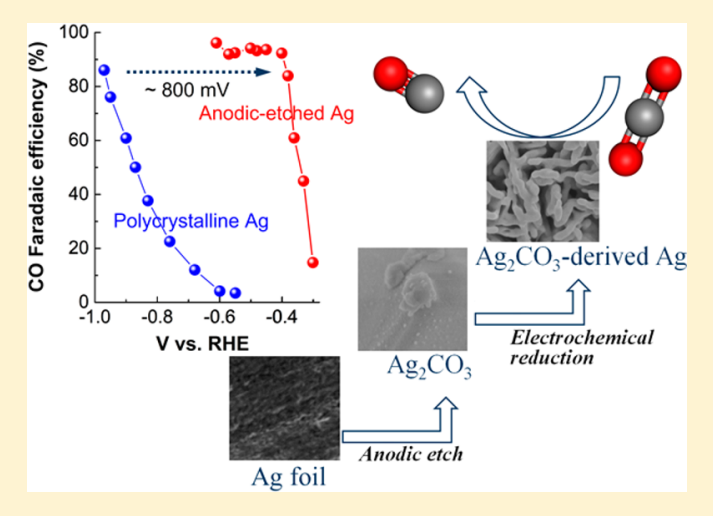

$\mathrm{T}$ he electrocatalytic conversion of $\mathrm{CO}_{2}$ into carbonbased fuels and valuable chemicals powered by renewable electricity is an attractive solution to both the utilization of captured $\mathrm{CO}_{2}$ and the storage of renewable energy. ${ }^{1-6}$ An essential step for achieving this goal is to find a highly efficient and selective electrocatalyst with long-term stability. ${ }^{7,8}$ Many transition metal catalysts have been evaluated for the selective reduction of $\mathrm{CO}_{2}$ in $\mathrm{CO}_{2}$-saturated aqueous solutions. ${ }^{2,9}$ Currently, the electrochemical conversion of $\mathrm{CO}_{2}$ into $\mathrm{CO}$ provides one of the most promising routes to form a cost-competitive product because syngas $\left(\mathrm{CO}\right.$ and $\left.\mathrm{H}_{2}\right)$ can be employed in Fischer-Tropsch synthesis to produce valueadded chemicals and synthetic fuels using already existing industrial technologies. ${ }^{1,4,10}$ Therefore, significant attention has been focused on finding electrocatalysts that can selectively produce $\mathrm{CO}$ from $\mathrm{CO}_{2}$. ${ }^{1-18}$

While $\mathrm{Au}$ is the most active surface for reducing $\mathrm{CO}_{2}$ selectively to $\mathrm{CO}$ among the identified metal catalysts, its potential for industrial applications is currently limited by its low abundance and high cost. In this context, $\mathrm{Ag}$ has great potential for large-scale applications due to its significantly lower cost than $\mathrm{Au}$ and high catalytic selectivity for the reduction of $\mathrm{CO}_{2}$ to $\mathrm{CO} .^{9-11,19-24}$ However, high overpotentials $(\eta)$ required for driving selective $\mathrm{CO}_{2}$ reduction and rapid catalytic deactivation in favor of $\mathrm{H}_{2}$ evolution on $\mathrm{Ag}$ catalysts significantly restrict its practical utilization. ${ }^{20,25}$
To overcome the limitations of Ag electrocatalysts, many attempts have focused on the development of nanostructured surfaces, which offer mass-transport advantages and contain more low-coordinated sites (edge sites and corner sites) that are more active for $\mathrm{CO}_{2}$ reduction in comparison with a planar metallic surface. ${ }^{7,10,14,22,26,27}$ It has been demonstrated that nanoporous Ag catalysts prepared by dealloying, ${ }^{10}$ Ag nanocoral catalysts synthesized via an oxidation-reduction process using chloride anions ${ }^{28}$ and oxide-derived nanostructured $\mathrm{Ag}^{22}$ are capable of electrochemically reducing $\mathrm{CO}_{2}$ to $\mathrm{CO}$ with dramatically enhanced catalytic selectivity at reduced overpotentials, which are ascribed to fast initial electron transfer for $\mathrm{CO}_{2}$ activation on these nanostructured catalysts. In addition, the catalytic stability of the electroreduction of $\mathrm{CO}_{2}$ to $\mathrm{CO}$ has been improved on nanostructured $\mathrm{Ag}$ catalysts, ${ }^{10,22,28}$ owing to the enhanced tolerance to heavy metal impurities in the electrolyte. ${ }^{27}$ While these previous attempts have significantly improved the performance of $\mathrm{Ag}$ electrocatalysts, it is still critical to develop a very simple, fast, scalable and low-cost method for preparing and maintaining higher-performance Ag

Received: March 23, 2018

Accepted: May 8, 2018

Published: May 8, 2018 
a
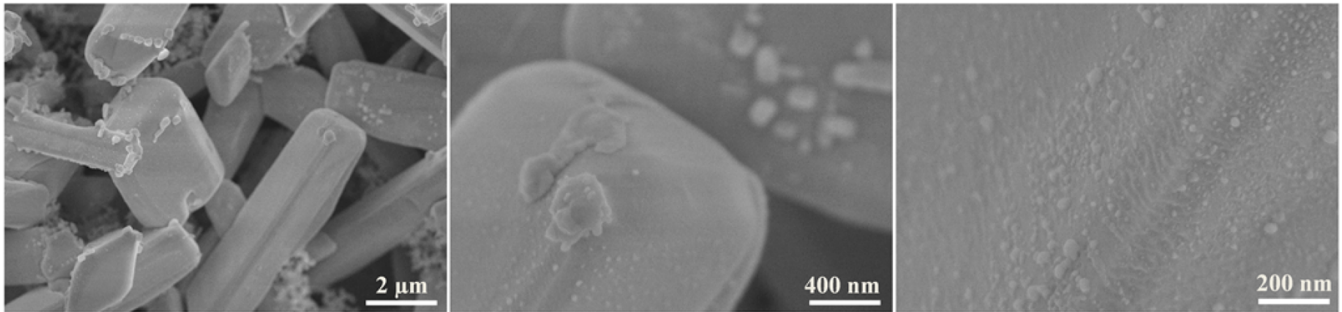

b
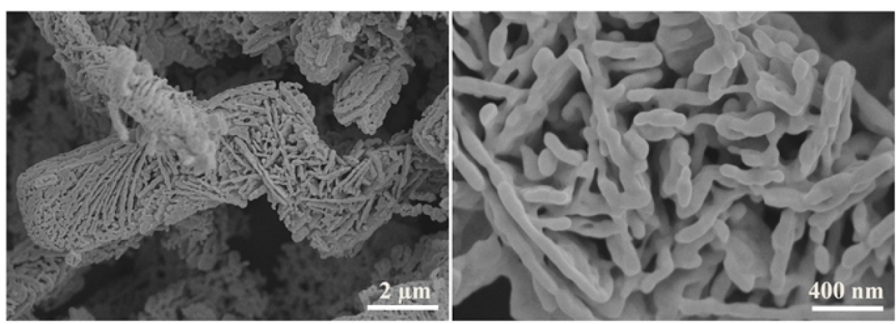

$\mathrm{C}$
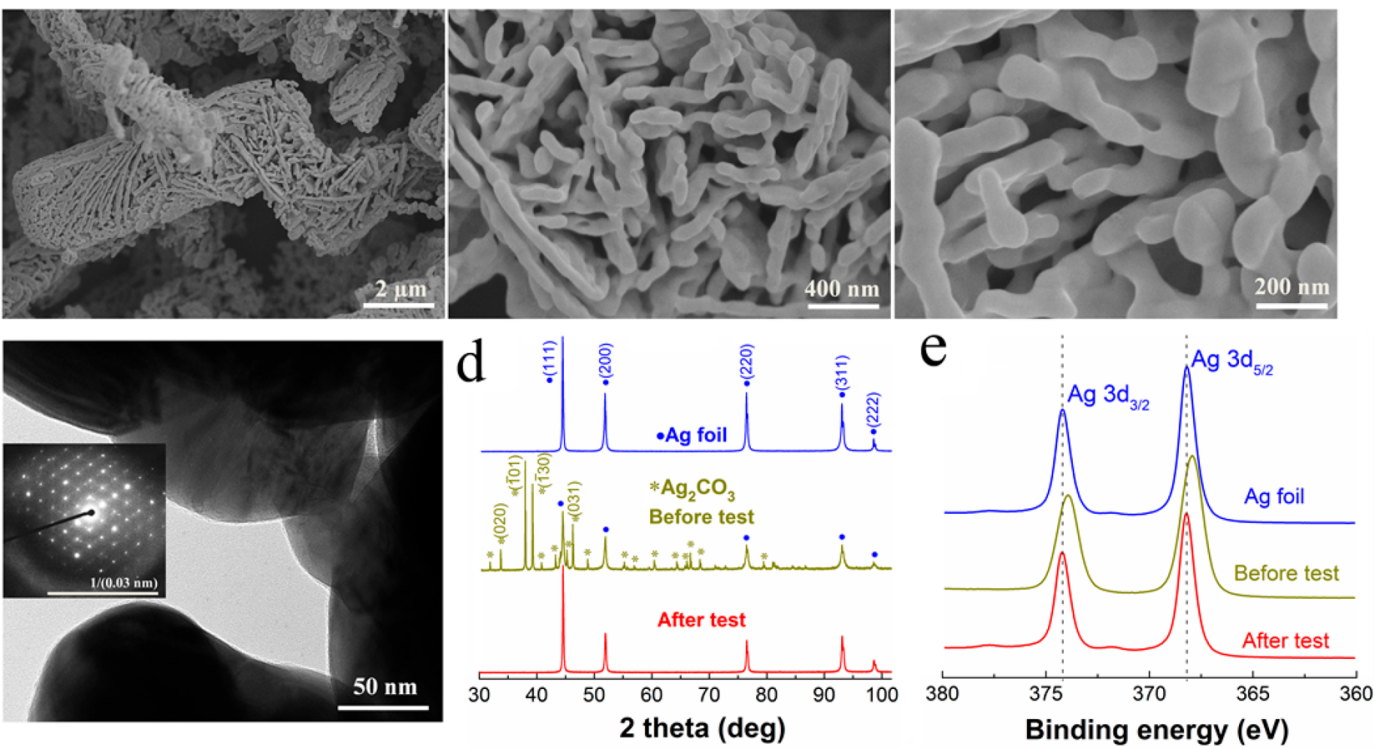

Figure 1. SEM images of anodic-etched $\mathrm{Ag}(\mathrm{AE}-\mathrm{Ag})(4.9 \mu \mathrm{m})$ before (a) and after (b) $\mathrm{CO}_{2}$ reduction electrolysis. (c) TEM image of AE-Ag after $\mathrm{CO}_{2}$ reduction electrolysis (the inset is the SAED pattern). (d) XRD patterns and (e) XPS spectra of untreated polycrystalline Ag (blue line) and $\mathrm{AE}-\mathrm{Ag}$ before (dark yellow line) and after (red line) $\mathrm{CO}_{2}$ reduction electrolysis, respectively.

electrocatalysts for practical applications of $\mathrm{CO}_{2}$ electroreduction.

Herein, we demonstrate a simple technique to prepare highly active, stable, and selective Ag electrocatalysts in $\mathrm{CO}_{2}$-saturated $\mathrm{KHCO}_{3}$ electrolyte that is used for $\mathrm{CO}_{2}$ reduction. By first anodic-etching $\mathrm{Ag}$ to form $\mathrm{Ag}_{2} \mathrm{CO}_{3}$ and then further reducing the $\mathrm{Ag}_{2} \mathrm{CO}_{3}$ to metallic $\mathrm{Ag}$ with a highly porous scaffold structure, a significantly reduced overpotential for high $\mathrm{CO}$ catalytic selectivity was achieved with remarkable catalytic stability, which outcompetes the reported $\mathrm{Ag}$ catalysts to date at identical conditions. Thus, the robust performance of the nanostructured catalysts formed via this very easy and low-cost synthesis method may offer a platform for practical applications of $\mathrm{CO}_{2}$ electroreduction.

For the electrochemical synthesis of Ag electrocatalysts used in this work, a polycrystalline $\mathrm{Ag}$ foil electrode was immersed in a $\mathrm{CO}_{2}$-saturated $0.1 \mathrm{M} \mathrm{KHCO}_{3}$ electrolyte in a twocompartment cell using a three-electrode configuration (a $\mathrm{Pt}$ counter electrode and a $\mathrm{Ag} / \mathrm{AgCl}$ reference electrode). The two-compartment cell was separated by a Nafion-115 proton exchange membrane to minimize impurity deposition during electrolysis. An anodic potential of $2.6 \mathrm{~V}$ vs the reversible hydrogen electrode (RHE) was applied on the $\mathrm{Ag}$ foil electrodes for $3 \mathrm{~min}$ to synthesize the $\mathrm{Ag}_{2} \mathrm{CO}_{3}$ layer, with an estimated thickness of $\sim 4.9 \mu \mathrm{m}$ (Table S1). The $\mathrm{Ag}_{2} \mathrm{CO}_{3}$ electrodes were then directly utilized for electrocatalytic $\mathrm{CO}_{2}$ reduction in $\mathrm{CO}_{2}$-saturated $0.1 \mathrm{M} \mathrm{KHCO}_{3}$ electrolyte and were electrochemically reduced to metallic $\mathrm{Ag}$ in the initial period $(<2 \mathrm{~min})$ of $\mathrm{CO}_{2}$ reduction electrolysis (Figure $\mathrm{S} 5 \mathrm{~d}$ ).
In the initial anodic-etching, the Ag electrodes formed short microporous polyhedral rod-like morphologies with smooth surfaces, as presented in Figure 1a, which is consistent with the reported morphologies of $\mathrm{Ag}_{2} \mathrm{CO}_{3}{ }^{29}$ Figure $1 \mathrm{~b}$ shows scanning electron microscope (SEM) images of the same electrodes after the electrolysis $(\sim 0.5 \mathrm{~h})$ of $\mathrm{CO}_{2}$ reduction, revealing that a nanoporous structure was formed via the electroreduction of $\mathrm{Ag}_{2} \mathrm{CO}_{3}$. In addition, transmission electron microscopy (TEM) confirmed that the size of the nanostructured materials after the $\mathrm{CO}_{2}$ reduction (Figure 1c), and the selected-area electron diffraction (SAED) pattern in the inset of Figure 1c exhibits the typical nature of crystals. To identify the phase of the prepared materials, X-ray diffraction (XRD) measurements were conducted. The XRD diffractograms in Figure 1d indicate that $\mathrm{Ag}_{2} \mathrm{CO}_{3}$ was formed by anodic-etching of $\mathrm{Ag}$ foil in $\mathrm{KHCO}_{3}$ solution. After $\mathrm{CO}_{2}$ reduction electrolysis, only $\mathrm{Ag}$ diffraction peaks were observed (Figure 1d) without any remaining $\mathrm{Ag}_{2} \mathrm{CO}_{3}$, indicating a full transformation from $\mathrm{Ag}_{2} \mathrm{CO}_{3}$ to metallic Ag.

To verify the surface composition of our samples, X-ray photoelectron spectroscopy (XPS) measurements were performed. As shown in Figure 1e, the $\mathrm{Ag} 3 \mathrm{~d}_{5 / 2}$ peak at $368.2 \mathrm{eV}$ was observed for polycrystalline Ag. For the anodic-etched Ag (AE-Ag) before $\mathrm{CO}_{2}$ reduction electrolysis, the $\mathrm{Ag} 3 \mathrm{~d}_{5 / 2}$ peak shifted by about $0.3 \mathrm{eV}$ to the binding energy of $367.9 \mathrm{eV}$ compared to the metal $\mathrm{Ag}$, which is consistent with the value of $\mathrm{Ag}^{+}$in the synthesized $\mathrm{Ag}_{2} \mathrm{CO}_{3}$ according to previous work. ${ }^{29-31}$ In addition, the binding energy of $288.7 \mathrm{eV}$ in $C_{1 s}$ spectra (Figure S3) represents the carbon associated with the carbonate $\left(\left(\mathrm{CO}_{3}\right)^{2-}\right),{ }^{32}$ which further confirms the formation 
a

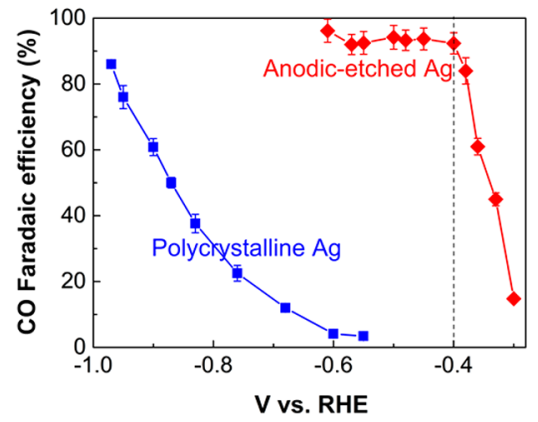

b

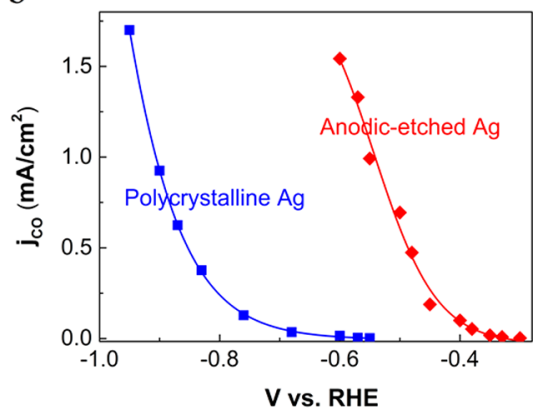

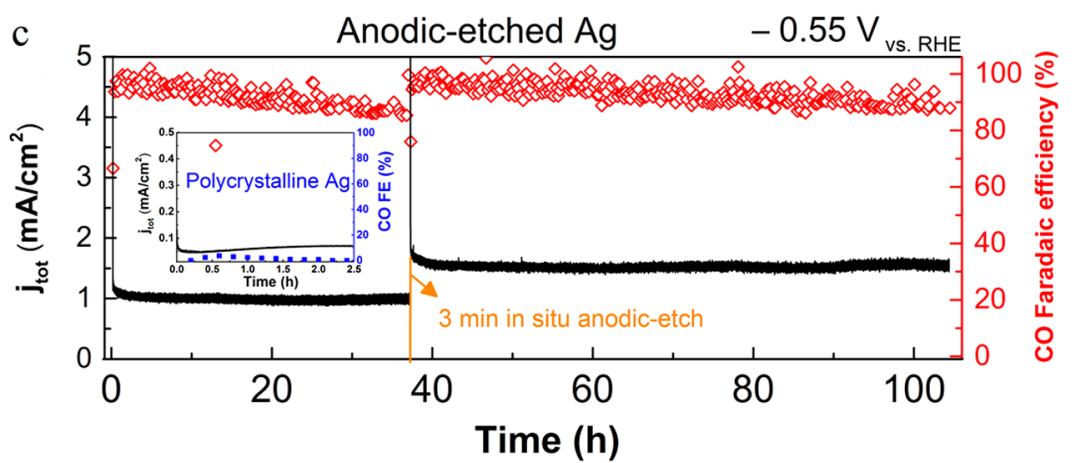

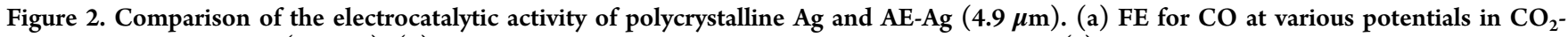
saturated $0.1 \mathrm{M} \mathrm{KHCO}_{3}(\mathrm{pH}$ 6.8). (b) Current density for $\mathrm{CO}$ formation at various potentials. (c) Catalytic stability performance for AE-Ag. The inset shows the catalytic stability of untreated polycrystalline Ag. All of the potentials were $i R$-corrected.

of $\mathrm{Ag}_{2} \mathrm{CO}_{3}$. After electrolysis, the $\mathrm{Ag} 3 \mathrm{~d}_{5 / 2}$ peak shifted back to $368.2 \mathrm{eV}$, corresponding to metallic $\mathrm{Ag}^{0.29-31}$ Furthermore, a surface valence band XPS spectrum of AE-Ag after electrolysis is in line with that of metallic Ag foil (Figure S4). All of the above results indicate that the reduction of $\mathrm{Ag}_{2} \mathrm{CO}_{3}$ to metallic $\mathrm{Ag}$ was complete, implying that only metallic $\mathrm{Ag}$ was present on $\mathrm{AE}-\mathrm{Ag}$ after $\mathrm{CO}_{2}$ reduction electrolysis.

Figure $2 \mathrm{a}$ presents a comparison of the electrocatalytic activity of $\mathrm{CO}_{2}$ reduction for untreated polycrystalline $\mathrm{Ag}$ (in blue) and $4.9 \mu \mathrm{m} \mathrm{AE}-\mathrm{Ag}$ (in red) at various applied potentials (iR-corrected potentials). Both the $\mathrm{AE}-\mathrm{Ag}$ and untreated $\mathrm{Ag}$ experienced a gradually enhanced Faradaic efficiency (FE) for $\mathrm{CO}$ production at more negative potentials (Figure 2a), simultaneously accompanying with a decrease in the related FE for $\mathrm{H}_{2}$ formation (Figure S6). Notably, the overpotential required for achieving $>90 \% \mathrm{FE}$ for $\mathrm{CO}$ production was shifted toward the positive potential by $\sim 800 \mathrm{mV}$ on AE-Ag compared to that of untreated Ag. More importantly, a high FE of more than $92 \%$ for $\mathrm{CO}$ formation was achieved on $\mathrm{AE}-\mathrm{Ag}$ at a potential of $-0.4 \mathrm{~V}$ vs RHE, which corresponds to an overpotential $\left(\eta_{\mathrm{co}}\right)$ as low as $0.29 \mathrm{~V}$ relative to the $\mathrm{CO}_{2} / \mathrm{CO}$ equilibrium potential of $-0.11 \mathrm{~V}$ vs $\mathrm{RHE}$, representing the highest catalytic selectivity for $\mathrm{CO}_{2}$ reduction to $\mathrm{CO}$ among the reported Ag catalysts at the same $\eta_{\text {co }}$ (Table S2). In contrast, no $\mathrm{CO}$ production was detected on untreated polycrystalline Ag at identical conditions $\left(\eta_{\mathrm{co}}=0.29 \mathrm{~V}\right)$. A plot of the partial current density for $\mathrm{CO}$ production $\left(j_{\mathrm{co}}\right)$ as a function of potential in Figure $2 \mathrm{~b}$ suggests that the onset potential for the reduction of $\mathrm{CO}_{2}$ to $\mathrm{CO}$ on $\mathrm{AE}-\mathrm{Ag}$ was $-0.3 \mathrm{~V}$ vs $\mathrm{RHE}\left(\eta_{\mathrm{co}}=0.19 \mathrm{~V}\right)$, which is a positive shift of $\sim 250 \mathrm{mV}$ in comparison with that $(-0.55 \mathrm{~V}$ vs $\mathrm{RHE})$ of untreated polycrystalline Ag. These results show that $\mathrm{Ag}_{2} \mathrm{CO}_{3}$-derived nanostructured $\mathrm{Ag}$ is a highly selective electrocatalyst for the electrocatalytic reduction of
$\mathrm{CO}_{2}$ to $\mathrm{CO}$ while inhibiting $\mathrm{H}_{2}$ evolution at significantly reduced overpotentials.

To test the electrocatalytic stability of AE-Ag catalysts, a long-term $\mathrm{CO}_{2}$ reduction measurement was performed on $\mathrm{AE}$ $\mathrm{Ag}$ at a fixed potential of $-0.55 \mathrm{~V}$ vs $\mathrm{RHE}\left(\mathrm{KHCO}_{3}\right.$ electrolyte without any purification was used). As shown in Figure $2 c$, AEAg exhibited an initially high geometric current density $\left(j_{\text {tot }}\right)$ at the early stage of electrolysis owing to the electroreduction of $\mathrm{Ag}_{2} \mathrm{CO}_{3}$ to $\mathrm{Ag}$ and subsequently a stable $j_{\text {tot }}$ of $\sim 1 \mathrm{~mA} / \mathrm{cm}^{2}$ with a $\mathrm{FE}$ of $\sim 90 \%$ for $\mathrm{CO}$ production over $\sim 37 \mathrm{~h}$. After $\sim 37$ $\mathrm{h}$, slight catalytic deactivation for $\mathrm{CO}$ formation was found, which may result from the deposition of impurities on the surface of the catalyst during the electrochemical reduction of $\mathrm{CO}_{2}{ }^{9,27}$ To overcome this slight deactivation, the same Ag catalyst electrodes were then held at an anodic potential of 2.6 $\mathrm{V}$ vs RHE for $3 \mathrm{~min}$ in the same $\mathrm{CO}_{2}$-saturated $\mathrm{KHCO}_{3}$ electrolyte, and after returning back to $-0.55 \mathrm{~V}$ vs RHE, a FE as high as $\sim 90 \%$ for CO formation was recovered and maintained for more than $60 \mathrm{~h}$ (no replacement of electrolyte during $>100$ $\mathrm{h}$ electrolysis). This remarkable stability significantly surpasses the currently reported durability for $\mathrm{CO}_{2}$ reduction on singleelement catalysts (Table S3) under similar conditions. The in situ reactivation of the catalysts may be attributed to the removal of impurities on the surface of the catalysts by anodicetching the contaminated surface. In contrast, the polycrystalline $\mathrm{Ag}$ electrodes had a very low $j_{\text {tot }}\left(\sim 0.07 \mathrm{~mA} / \mathrm{cm}^{2}\right)$ and a very low $\mathrm{FE}$ for $\mathrm{CO}$, which decreased from 3.4 to $0 \%$ over the course of $2.5 \mathrm{~h}$ at $-0.55 \mathrm{~V}$ vs RHE, which indicates fast catalytic deactivation. Thus, the Ag resulting from AE-Ag exhibited high catalytic selectivity and activity with long-term stability for the electrocatalytic reduction of $\mathrm{CO}_{2}$ to $\mathrm{CO}$.

The electrochemical active surface area (EASA) of nanoporous $\mathrm{Ag}$ catalysts reduced from $\mathrm{AE}-\mathrm{Ag}$ and untreated polycrystalline $\mathrm{Ag}$ was measured by forming a monolayer 
oxide on $\mathrm{Ag}$ surface in $0.1 \mathrm{M} \mathrm{KOH} .^{20}$ The charge used for oxidizing the monolayer of the Ag surface was calculated in Figure S7, which shows that the EASA of nanoporous $\mathrm{Ag}$ catalysts reduced from $\mathrm{AE}-\mathrm{Ag}(3 \mathrm{~min})$ is more than 10-fold larger than that of untreated $\mathrm{Ag}$, resulting in the discrepancy of $j_{\text {tot }}$ between AE-Ag $\left(\sim 1 \mathrm{~mA} / \mathrm{cm}^{2}\right)$ and untreated $\mathrm{Ag}(\sim 0.07$ $\left.\mathrm{mA} / \mathrm{cm}^{2}\right)$, as shown in Figure $2 \mathrm{c}$. Thus, the increased number of active sites (increased EASA) reflects the enhanced catalytic reaction rate. In addition, the normalized $j_{\text {co }}$ of AE-Ag by EASA $\left(\sim 0.08 \mathrm{~mA} / \mathrm{cm}^{2}\right)$ is $\sim 40$ times higher in comparison with that $\left(\sim 0.002 \mathrm{~mA} / \mathrm{cm}^{2}\right)$ of untreated $\mathrm{Ag}$, indicating significantly improved intrinsic $\mathrm{CO}_{2}$ reduction activity on nanoporous $\mathrm{Ag}$ catalysts reduced from $\mathrm{Ag}_{2} \mathrm{CO}_{3}$.

The thickness effect of AE-Ag on the catalytic performance was also evaluated. In this work, the average thickness of AE-Ag was tuned by systematically varying the anodic-etching time (Table S1). As shown in Figure 3a, the thickness of AE-Ag is
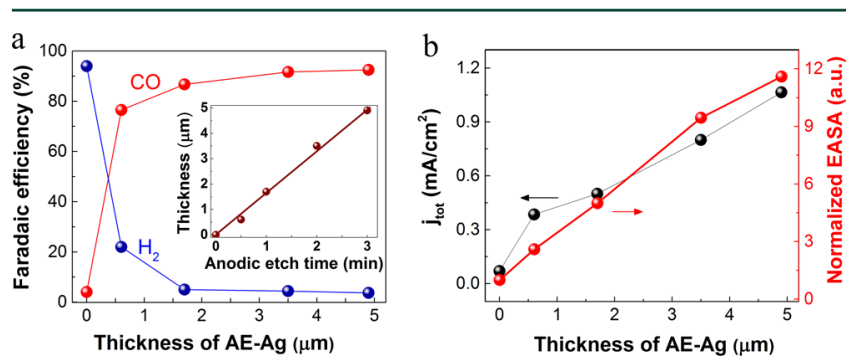

Figure 3. Electrocatalytic activity as a function of the thickness of AE-Ag at $-0.55 \mathrm{~V}$ vs RHE. (a) FE for $\mathrm{CO}$ and $\mathrm{H}_{2}$ on AE-Ag with different thickness in $\mathrm{CO}_{2}$-saturated $0.1 \mathrm{M} \mathrm{KHCO}_{3}(\mathrm{pH}$ 6.8). The inset shows the thickness for different anodic-etching times. (b) Geometric current density and normalized EASA.

linearly correlated with the anodic-etching time, and an gradually enhanced FE for $\mathrm{CO}$ formation was observed along with decreased $\mathrm{FE}$ for $\mathrm{H}_{2}$ evolution at $-0.55 \mathrm{~V}$ vs $\mathrm{RHE}$ with increasing thickness $(\leq 3.5 \mu \mathrm{m})$ of AE-Ag. While a high FE of $>90 \%$ for $\mathrm{CO}$ formation was achieved on both 3.5 and $4.9 \mu \mathrm{m}$ AE-Ag (Figure 3a), the distinct thickness leads to a discrepancy of $j_{\text {tot }}$ between the two catalysts (Figure 3b). The EASA was enhanced with increasing thickness of AE-Ag (Figure 3b), which led to the correspondingly increased $j_{\text {tot }}$ and $j_{\text {co }}$ (Figure S8). These results indicate that the thicker nanoporous $\mathrm{Ag}$ is able to provide more active sites for the reduction of $\mathrm{CO}_{2}$ to CO.

It has been reported that the surface facets of $\mathrm{Ag}$ could significantly influence the catalytic activity of $\mathrm{CO}_{2}$ reduction. ${ }^{20,33}$ To reveal the variation of Ag surface facets before and after anodic treatment, the adsorption/desorption of $\mathrm{OH}^{-}$was performed on $\mathrm{AE}-\mathrm{Ag}$ and untreated $\mathrm{Ag}$ in argon-purged $0.1 \mathrm{M}$ $\mathrm{KOH}$ in the potential range from $\sim-0.3$ to $\sim 1 \mathrm{~V}$ vs $\mathrm{RHE}$ (double layer region) at room temperature. ${ }^{34-36}$ Figure $4 \mathrm{a}$ exhibits the difference in peak potentials for the $\mathrm{OH}^{-}$ adsorption/desorption processes between $\mathrm{AE}-\mathrm{Ag}$ (red) and polycrystalline $\mathrm{Ag}$ (blue), which correlate with the distinct surface facets of the two catalysts. ${ }^{34-36}$ In addition, cyclic voltammetry of oxide-derived Ag reported in our previous work $^{22}$ was also conducted in argon-purged $0.1 \mathrm{M} \mathrm{KOH}$, which shows different peak potentials compared to AE-Ag (Figure S11), reflecting different dominant facets of the Ag surface. While the specific facets of the Ag surface could not be identified, the obvious discrepancy in $\mathrm{Ag}$ surface facets may contribute to the difference of the catalytic performance in the
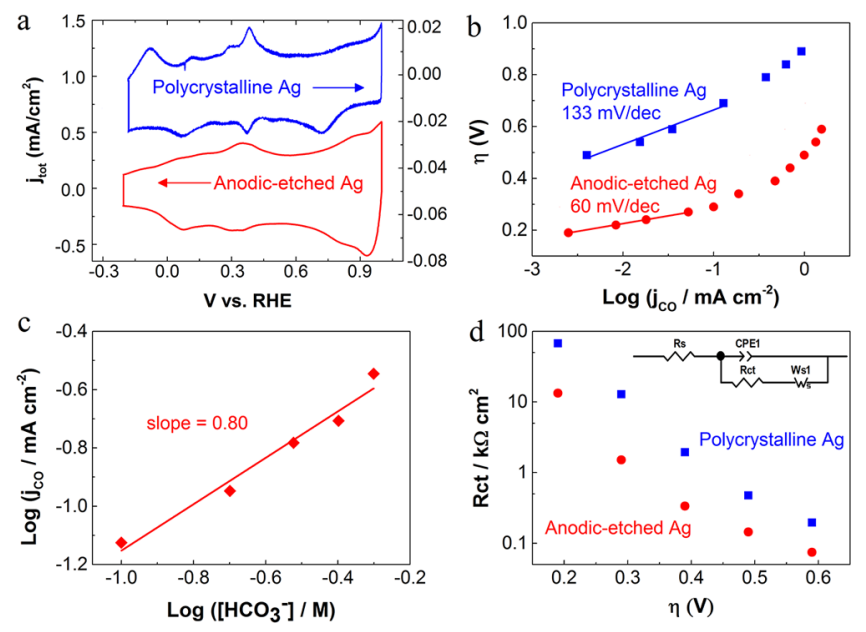

Figure 4. (a) Cyclic voltammetry curves of untreated polycrystalline $\mathrm{Ag}$ (blue line) and AE-Ag $(4.9 \mu \mathrm{m})$ (red line) in argon-purged 0.1 $\mathrm{M} \mathrm{KOH}$ at room temperature with a sweep rate of $50 \mathrm{mV} / \mathrm{s}$. (b) Tafel plots of the CO partial current density for polycrystalline $\mathrm{Ag}$ and AE-Ag $(4.9 \mu \mathrm{m})$. (c) Bicarbonate concentration at constant potentials of $\mathrm{AE}-\mathrm{Ag}$. (d) Charge transfer resistance at various overpotentials. The inset shows the equivalent circuit for the metal/solution interface $\left(R_{c t}, R_{s}, C P E\right.$ and $W_{s}$ are charge transfer resistance, solution resistance, constant phase element, and Warburg-short circuit terminus, respectively).

reduction of $\mathrm{CO}_{2}$. Therefore, in addition to the increased EASA in the anodic-etched nanostructured $\mathrm{Ag}$ compared to polycrystalline $\mathrm{Ag}$, we also provide evidence of a different surface electronic structure that could also influence the catalytic activity and selectivity.

In order to gain insight into the electrokinetic mechanism of $\mathrm{CO}_{2}$ reduction on $\mathrm{AE}-\mathrm{Ag}$ and untreated polycrystalline $\mathrm{Ag}$, Tafel analysis was performed. It has been demonstrated that a two-electron transfer is involved for $\mathrm{CO}_{2}$ reduction to $\mathrm{CO}$, and each electron transfer is followed with one proton donation step (or proton-coupled electron transfer steps based on computational studies $\left.{ }^{37-40}\right) .^{7,9,10,22,27}$ Of particular note, the initial electron transfer for $\mathrm{CO}_{2}$ activation (stabilization of $\mathrm{CO}_{2}{ }^{--}$or $\mathrm{COOH}^{\bullet}$ ) is the rate-determining step (RDS) in the whole process due to the much higher activation energy barrier for the first electron transfer compared to the following steps. $^{10,20}$ In our study, a Tafel plot of untreated Ag (overpotential versus $\log$ of the partial current density for $\mathrm{CO}$ production) in Figure 4b shows a Tafel slope of $133 \mathrm{mV} /$ dec, which implies that the initial electron transfer for $\mathrm{CO}_{2}$ activation is the RDS for the overall process (Scheme 1). ${ }^{10,16}$ In contrast, a low Tafel slope of $60 \mathrm{mV} / \mathrm{dec}$ was obtained on AEinduced nanostructured Ag catalysts $(4.9 \mu \mathrm{m})$ at relatively low overpotentials, indicating fast initial electron transfer to a $\mathrm{CO}_{2}$ molecule for $\mathrm{CO}_{2}$ activation (Scheme 1). ${ }^{10,25}$ In addition, this low Tafel slope is consistent with a fast pre-equilibrium of the initial electron transfer prior to a RDS according to previous work. ${ }^{25}$ Furthermore, a dramatically increased Tafel slope for nanostructured $\mathrm{Ag}$ was observed at relatively high overpotentials, implying that the electrocatalytic $\mathrm{CO}_{2}$ reduction likely reaches a mass transport limitation.

It has been demonstrated that the initial proton donation is derived from $\mathrm{HCO}_{3}{ }^{-20,25}$ Thus, to further uncover the reaction mechanism (first proton donation step) on nanostructured $\mathrm{Ag}$, the effect of $\mathrm{HCO}_{3}^{-}$concentration on the $\mathrm{CO}_{2}$ reduction activity was investigated. A plot of $\log \left(j_{\mathrm{co}}\right)$ versus $\log$ - 
Scheme 1. Proposed Reaction Paths for $\mathrm{CO}_{2}$ Reduction to $\mathrm{CO}$ on Untreated $\mathrm{Ag}$ and $\mathrm{Ag}_{2} \mathrm{CO}_{3}$-Derived Nanostructured $\mathrm{Ag}^{a}$
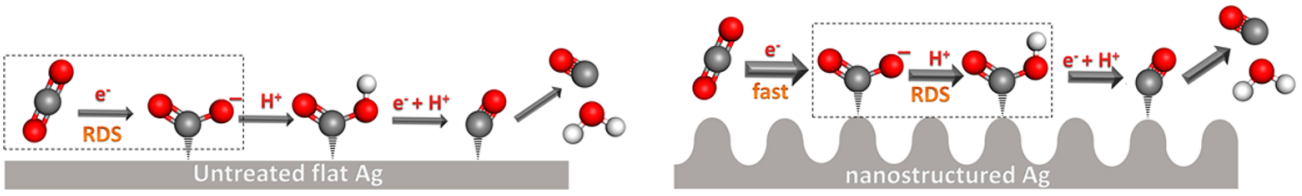

${ }^{a_{T}}$ The grey, red, and white balls represent $\mathrm{C}, \mathrm{O}$, and $\mathrm{H}$ atoms, respectively. Larger arrows indicate the relatively fast reaction steps.

$\left(\left[\mathrm{HCO}_{3}{ }^{-}\right]\right)$in Figure $4 \mathrm{c}$ exhibits a slope of $\sim 0.8$, which corresponds to first-order dependence of the $\mathrm{HCO}_{3}{ }^{-}$ concentration on the reaction rate, indicating that proton donation from $\mathrm{HCO}_{3}{ }^{-}$is a RDS for nanostructured $\mathrm{Ag}$ in the reduction of $\mathrm{CO}_{2}$ to $\mathrm{CO} .{ }^{10,25}$ Thus, the RDS is switched from the first electron transfer for untreated $\mathrm{Ag}$ to the initial proton donation for nanostructured Ag (Scheme 1).

To better understand the charge transfer process at the electrode/electrolyte interface, electrochemical impedance spectroscopy (EIS) was performed at various potentials. The comparison of charge transfer resistance $\left(\mathrm{R}_{\mathrm{ct}}\right)$ between untreated $\mathrm{Ag}$ and $\mathrm{AE}-\mathrm{Ag}$ as a function of overpotential was extracted from EIS (Figure S9) based on the equivalent circuit (Figure 4d). As presented in Figure 4d, AE-Ag exhibited a much lower $R_{c t}$ than that of polycrystalline $A g$ at identical conditions, suggesting a significantly accelerated charge transfer process on $\mathrm{AE}-\mathrm{Ag},{ }^{14}$ which may reflect the reduced activation energy barrier of electron transfer on nanostructured Ag. This result is consistent with fast initial electron transfer on nanostructured $\mathrm{Ag}$ according to Tafel analysis. In addition, a clear mass transport limitation for nanoporous Ag was observed at relatively high overpotentials in Nyquist plots (Figure S10), which is also in line with Tafel analysis (the dramatic increase in the Tafel slope at relatively high overpotentials). These results indicate that, while a mass transport limitation may be reached on nanoporous $\mathrm{Ag}$ at high overpotentials, the dramatically improved initial electron transfer for $\mathrm{CO}_{2}$ activation enhances the intrinsic $\mathrm{CO}_{2}$ reduction activity, resulting in high catalytic selectivity and activity for the electrocatalytic reduction of $\mathrm{CO}_{2}$ to $\mathrm{CO}$. EIS has seldom been used in $\mathrm{CO}_{2}$ reduction experiments; thereby, the consistency between the Tafel analysis and EIS shows the potential for this technique to give meaningful information relating to mechanistic charge transfer processes for electrochemical $\mathrm{CO}_{2}$ reduction.

In summary, a simple and fast anodic-etching procedure was used to fabricate highly active, selective, and stable $\mathrm{Ag}$ electrocatalysts for the reduction of $\mathrm{CO}_{2}$ to $\mathrm{CO}$. A high $\mathrm{FE}$ of $>92 \%$ for $\mathrm{CO}$ was achieved on $\mathrm{AE}-\mathrm{Ag}$ at a potential of -0.4 $\mathrm{V}$ vs RHE (overpotential of $290 \mathrm{mV}$ ). Notably, the AE-Ag was capable of maintaining a high catalytic selectivity of $\sim 90 \%$ for $\mathrm{CO}$ production for $>100 \mathrm{~h}$, which remarkably outcompetes the currently reported durability of single-metal catalysts. The improved $\mathrm{CO}_{2}$ reduction performance is attributed to the increased number of active sites for $\mathrm{CO}_{2}$ reduction and the improved intrinsic $\mathrm{CO}_{2}$ reduction activity by fast initial electron transfer. In this study, after prolonged $\mathrm{CO}_{2}$ reduction, the procedure of anodic-etching can be performed subsequently on the same $\mathrm{Ag}$ electrocatalysts in the same $\mathrm{KHCO}_{3}$ electrolyte that is used for $\mathrm{CO}_{2}$ reduction to recover the robust catalytic performance. Thus, the Ag electrocatalysts, prepared by this fast, simple, and cost-effective approach, is capable of reducing $\mathrm{CO}_{2}$ to $\mathrm{CO}$ with high catalytic selectivity and excellent stability, offering a very promising platform for industrial applications.

\section{ASSOCIATED CONTENT}

S Supporting Information

The Supporting Information is available free of charge on the ACS Publications website at DOI: 10.1021/acsenergylett.8b00472.

Experimental details of $\mathrm{Ag}_{2} \mathrm{CO}_{3}$ fabrication, SEM, TEM, XRD, XPS, and $\mathrm{CO}_{2}$ reduction measurement, thickness calculation of anodic-etched $\mathrm{Ag}$, summarized tables of reported electrocatalysts, EASA measurement, calculation of $j_{\mathrm{CO}}$ and normalized $j_{\mathrm{CO}}, \mathrm{EIS}, \mathrm{OH}^{-}$adsorption/ desorption, $i R$ correction, and error bars (PDF)

\section{AUTHOR INFORMATION}

\section{Corresponding Authors}

*E-mail: m.ma.cn@outlook.com (M.M.).

*E-mail: W.Smith@tudelft.nl (W.A.S.).

ORCID ब

Ming Ma: 0000-0003-3561-5710

Wilson A. Smith: 0000-0001-7757-5281

\section{Notes}

The authors declare no competing financial interest.

\section{ACKNOWLEDGMENTS}

This work is supported by an NWO VIDI grant awarded to W.A.S. The authors would like to thank Bartek J. Trześniewski for performing the XPS measurements. We also would like to thank Zerui Zhang for assistance in part of the proton transfer study experiments.

\section{REFERENCES}

(1) Whipple, D. T.; Kenis, P. J. A. Prospects of $\mathrm{CO}_{2}$ utilization via direct heterogeneous electrochemical reduction. J. Phys. Chem. Lett. 2010, 1, 3451-3458.

(2) Kuhl, K. P.; Hatsukade, T.; Cave, E. R.; Abram, D. N.; Kibsgaard, J.; Jaramillo, T. F. Electrocatalytic conversion of carbon dioxide to methane and methanol on transition metal surfaces. J. Am. Chem. Soc. 2014, 136, 14107-14113.

(3) Qiao, J.; Liu, Y.; Hong, F.; Zhang, J. A review of catalysts for the electroreduction of carbon dioxide to produce low-carbon fuels. Chem. Soc. Rev. 2014, 43, 631-675.

(4) Ross, M. B.; Dinh, C. T.; Li, Y.; Kim, D.; De Luna, P.; Sargent, E. $\mathrm{H}$.; Yang, P. Tunable $\mathrm{Cu}$ enrichment enables designer syngas electrosynthesis from $\mathrm{CO}_{2}$. J. Am. Chem. Soc. 2017, 139, 9359-9363.

(5) Li, C. W.; Ciston, J.; Kanan, M. W. Electroreduction of carbon monoxide to liquid fuel on oxide-derived nanocrystalline copper. Nature 2014, 508, 504-507.

(6) Ma, M.; Djanashvili, K.; Smith, W. A. Controllable hydrocarbon formation from the electrochemical reduction of $\mathrm{CO}_{2}$ over $\mathrm{Cu}$ nanowire arrays. Angew. Chem., Int. Ed. 2016, 55, 6680-6684.

(7) Li, C. W.; Kanan, M. W. $\mathrm{CO}_{2}$ reduction at low overpotential on $\mathrm{Cu}$ electrodes resulting from the reduction of thick $\mathrm{Cu}_{2} \mathrm{O}$ films. J. Am. Chem. Soc. 2012, 134, 7231-7234.

(8) Li, F.; Chen, L.; Knowles, G. P.; MacFarlane, D. R.; Zhang, J. Hierarchical mesoporous $\mathrm{SnO}_{2}$ nanosheets on carbon cloth: a robust 
and flexible electrocatalyst for $\mathrm{CO}_{2}$ reduction with high efficiency and selectivity. Angew. Chem., Int. Ed. 2017, 56, 505-509.

(9) Hori, Y. Electrochemical $\mathrm{CO}_{2}$ Reduction on Metal Electrodes. In Modern Aspects of Electrochemistry; Vayenas, C. G., White, R. E., Gamboa-Aldeco, M. E., Eds.; Springer, 2008; pp 89-189.

(10) Lu, Q.; Rosen, J.; Zhou, Y.; Hutchings, G. S.; Kimmel, Y. C.; Chen, J. G.; Jiao, F. A selective and efficient electrocatalyst for carbon dioxide reduction. Nat. Commun. 2014, 5, 3242.

(11) Hatsukade, T.; Kuhl, K. P.; Cave, E. R.; Abram, D. N.; Jaramillo, T. F. Insights into the electrocatalytic reduction of $\mathrm{CO}_{2}$ on metallic silver surfaces. Phys. Chem. Chem. Phys. 2014, 16, 13814-13819.

(12) Lee, H.-E.; Yang, K. D.; Yoon, S. M.; Ahn, H.-Y.; Lee, Y. Y.; Chang, H.; Jeong, D. H.; Lee, Y.-S.; Kim, M. Y.; Nam, K. T. Concave rhombic dodecahedral Au nanocatalyst with multiple high-index facets for $\mathrm{CO}_{2}$ reduction. ACS Nano 2015, 9, 8384-8393.

(13) Hall, A. S.; Yoon, Y.; Wuttig, A.; Surendranath, Y. Mesostructure-induced selectivity in $\mathrm{CO}_{2}$ reduction catalysis. J. Am. Chem. Soc. 2015, 137, 14834-14837.

(14) Liu, M.; Pang, Y.; Zhang, B.; De Luna, P.; Voznyy, O.; Xu, J.; Zheng, X.; Dinh, C. T.; Fan, F.; Cao, C.; et al. Enhanced electrocatalytic $\mathrm{CO}_{2}$ reduction via field-induced reagent concentration. Nature 2016, 537, 382-386.

(15) Asadi, M.; Kumar, B.; Behranginia, A.; Rosen, B. A.; Baskin, A.; Repnin, N.; Pisasale, D.; Phillips, P.; Zhu, W.; Haasch, R.; et al. Robust carbon dioxide reduction on molybdenum disulphide edges. Nat. Commun. 2014, 5, 4470.

(16) Kas, R.; Hummadi, K. K.; Kortlever, R.; De Wit, P.; Milbrat, A.; Luiten-Olieman, M. W. J.; Benes, N. E.; Koper, M. T. M.; Mul, G. Three-dimensional porous hollow fibre copper electrodes for efficient and high-rate electrochemical carbon dioxide reduction. Nat. Commun. 2016, 7, 10748 .

(17) Vasileff, A.; Zheng, Y.; Qiao, S. Z. Carbon solving carbon's problems: recent progress of nanostructured carbon-based catalysts for the electrochemical reduction of $\mathrm{CO}_{2}$. Adv. Energy Mater. 2017, 7, 1700759.

(18) Cui, X.; Pan, Z.; Zhang, L.; Peng, H.; Zheng, G. Selective etching of nitrogen-doped carbon by steam for enhanced electrochemical $\mathrm{CO}_{2}$ reduction. Adv. Energy Mater. 2017, 7, 1701456.

(19) Kim, C.; Jeon, H. S.; Eom, T.; Jee, M. S.; Kim, H.; Friend, C. M.; Min, B. K.; Hwang, Y. J. Achieving selective and efficient electrocatalytic activity for $\mathrm{CO}_{2}$ reduction using immobilized silver nanoparticles. J. Am. Chem. Soc. 2015, 137, 13844-13850.

(20) Rosen, J.; Hutchings, G. S.; Lu, Q.; Rivera, S.; Zhou, Y.; Vlachos, D. G.; Jiao, F. Mechanistic insights into the electrochemical reduction of $\mathrm{CO}_{2}$ to $\mathrm{CO}$ on nanostructured Ag surfaces. ACS Catal. 2015, 5, 4293-4299.

(21) Qiu, J.; Tang, J.; Shen, J.; Wu, C.; Qian, M.; He, Z.; Chen, J.; Shuang, S. Preparation of a silver electrode with a three-dimensional surface and its performance in the electrochemical reduction of carbon dioxide. Electrochim. Acta 2016, 203, 99-108.

(22) Ma, M.; Trześniewski, B. J.; Xie, J.; Smith, W. A. Selective and efficient reduction of carbon dioxide to carbon monoxide on oxidederived nanostructured silver electrocatalysts. Angew. Chem., Int. Ed. 2016, 55, 9748-9752.

(23) Yoon, Y.; Hall, A. S.; Surendranath, Y. Tuning of silver catalyst mesostructure promotes selective carbon dioxide conversion into fuels. Angew. Chem., Int. Ed. 2016, 55, 15282-15286.

(24) Vermaas, D. A.; Smith, W. A. Synergistic electrochemical $\mathrm{CO}_{2}$ reduction and water oxidation with a bipolar membrane. ACS Energy Lett. 2016, 1, 1143-1148.

(25) Chen, Y.; Li, C. W.; Kanan, M. W. Aqueous $\mathrm{CO}_{2}$ reduction at very low overpotential on oxide-derived Au nanoparticles. J. Am. Chem. Soc. 2012, 134, 19969-19972.

(26) Ma, M.; Djanashvili, K.; Smith, W. A. Selective electrochemical reduction of $\mathrm{CO}_{2}$ to $\mathrm{CO}$ on $\mathrm{CuO}$-derived $\mathrm{Cu}$ nanowires. Phys. Chem. Chem. Phys. 2015, 17, 20861-20867.

(27) Lu, Q.; Rosen, J.; Jiao, F. Nanostructured metallic electrocatalysts for carbon dioxide reduction. Chem CatChem 2015, 7, 38-47.
(28) Hsieh, Y.-C.; Senanayake, S. D.; Zhang, Y.; Xu, W.; Polyansky, D. E. Effect of chloride anions on the synthesis and enhanced catalytic activity of silver nanocoral electrodes for $\mathrm{CO}_{2}$ electroreduction. ACS Catal. 2015, 5, 5349-5356.

(29) Dong, H.; Chen, G.; Sun, J.; Li, C.; Yu, Y.; Chen, D. A novel high-efficiency visible-light sensitive $\mathrm{Ag}_{2} \mathrm{CO}_{3}$ photocatalyst with universal photodegradation performances: Simple synthesis, reaction mechanism and first-principles study. Appl. Catal., B 2013, 134-135, $46-54$.

(30) Murray, B. J.; Li, Q.; Newberg, J. T.; Menke, E. J.; Hemminger, J. C.; Penner, R. M. Shape- and size-selective electrochemical synthesis of dispersed silver(1) oxide colloids. Nano Lett. 2005, 5, 2319-2324.

(31) Yu, C.; Li, G.; Kumar, S.; Yang, K.; Jin, R. Phase transformation synthesis of novel $\mathrm{Ag}_{2} \mathrm{O} / \mathrm{Ag}_{2} \mathrm{CO}_{3}$ heterostructures with high visible light efficiency in photocatalytic degradation of pollutants. Adv. Mater. 2014, 26, 892-898.

(32) Chan, C.; Wu, J.; Li, J.; Cheung, Y. Polypropylene/calcium carbonate nanocomposites. Polymer 2002, 43, 2981-2992.

(33) Hoshi, N.; Kato, M.; Hori, Y. Electrochemical reduction of $\mathrm{CO}_{2}$ on single crystal electrodes of silver $\mathrm{Ag}(111), \mathrm{Ag}(100)$ and $\mathrm{Ag}(110) . \mathrm{J}$. Electroanal. Chem. 1997, 440, 283-286.

(34) Blizanac, B. B.; Ross, P. N.; Marković, N. M. Oxygen reduction on silver low-index single-crystal surfaces in alkaline solution: rotating ring disk $\mathrm{Ag}_{\mathrm{Agkl}}$ studies. J. Phys. Chem. B 2006, 110, 4735-4741.

(35) Jovic, B. M.; Jovic, V. D.; Stafford, G. R. Cyclic voltammetry on $\operatorname{Ag}(111)$ and $\operatorname{Ag}(100)$ faces in sodium hydroxide solutions. Electrochem. Commun. 1999, 1, 247-251.

(36) Horswell, S. L.; Pinheiro, A. L. N.; Savinova, E. R.; Danckwerts, M.; Pettinger, B.; Zei, M.-S.; Ertl, G. A comparative study of hydroxide adsorption on the (111), (110), and (100) faces of silver with cyclic voltammetry, ex situ electron diffraction, and in situ second harmonic generation. Langmuir 2004, 20, 10970-10981.

(37) Kortlever, R.; Shen, J.; Schouten, K. J. P.; Calle-Vallejo, F.; Koper, M. T. M. Catalysts and reaction pathways for the electrochemical reduction of carbon dioxide. J. Phys. Chem. Lett. 2015, 6, 4073-4082.

(38) Calle-Vallejo, F.; Koper, M. T. M. Theoretical considerations on the electroreduction of $\mathrm{CO}$ to $\mathrm{C}_{2}$ species on $\mathrm{Cu}(100)$ electrodes. Angew. Chem., Int. Ed. 2013, 52, 7282-7285.

(39) Peterson, A. A.; Abild-Pedersen, F.; Studt, F.; Rossmeisl, J.; Nørskov, J. K. How copper catalyzes the electroreduction of carbon dioxide into hydrocarbon fuels. Energy Environ. Sci. 2010, 3, 1311.

(40) Hansen, H. A.; Varley, J. B.; Peterson, A. A.; Nørskov, J. K. Understanding trends in the electrocatalytic activity of metals and enzymes for $\mathrm{CO}_{2}$ reduction to CO. J. Phys. Chem. Lett. 2013, 4, 388392. 